\title{
Polymer Concrete as Construction Materials
}

\author{
Kyu-Seok YEON \\ Department of Regional Infrastructure Engineering, Kangwon National University, \\ Chuncheon, 200-701 Republic of Korea \\ E-mail:ksyeon@kangwon.ac.kr
}

\begin{abstract}
Since 1950s, there has been increasing interest on concrete-polymer composites as new construction materials in the construction industry. The concrete-polymer composites, typically, can be classified into three types in terms of principles of the process technology, i.e. polymer cement concrete, polymer concrete, and polymer impregnated concrete. Among them, the polymer concrete is well known for its versatile and beneficial structural applications compared to the other types. In this paper, physical and mechanical properties, product applications, economic analysis, and environmental effects of the polymer concrete will be mainly addressed. Furthermore, anticipated prospect of the polymer concrete in the construction market will be also discussed.
\end{abstract}

Key Words : concrete-polymer composites ; polymer concrete ; mechanical properties ; product applications ; environmental effects

\section{INTRODUCTION}

It is not a quite new trial to use concrete polymer composites in constructions. According to the historical background of polymers in concrete, it has been known that construction materials modified by polymers were already used in job site applications in 2000 3000 B.C. Since emphasize has been made on increasing number of precast product applications in the recent constructions, it is absolutely true that importance of concrete-polymer composites is getting greater and greater. Above all, polymer concrete is suitable for making precast produces. Better understanding of properties and characteristics of the concrete will give rise to the development in entire construction technologies in the present and future as well. In this report, several important aspects of the polymer concrete will be evaluated and described by comparing with cement concrete.

\section{CLSSIFICATION OF CONCRETE- POLYMER COMPOSITES}

Concrete-polymer composites can be defined as materials produced by partly or entirely replacing the hydraulic cement binder portion of conventional mortar and concrete with polymeric binders for physical and mechanical properties improvement. Typically, the concrete-polymer composites are classified into three types dependent on the principles of process technology : ${ }^{1,2,3,4)}$

1) Polymer cement concrete (PCC)

2) Polymer concrete (PC)

3) Polymer impregnated concrete (PIC)

PC can be defined as a material composed of aggregate, filler, and polymeric binder, which is made by fully replacing the hydraulic cement portion of conventional concrete with polymeric binders or liquid resins such as unsaturated polyester, epoxy,
PMMA and polyurethane.

\section{MATERIAL PROPERTIES OF PC}

\subsection{Physical and Mechanical Properties}

As seen in Table 1, PC showed remarkable mechanical and physical properties compared to cement concrete.

Especially, PC had much greater mechanical strength, one of the representative marks for engineering property evaluation, than the cement concrete.

Besides of mechanical strengths, it turned out that PC has the beneficial performances as construction materials in overall properties.

\subsection{Chemical Resistance}

Since resin helps to develop great high water-tightness and impermeability by forming dense microstructures, PC tends to have excellent resistance against the penetration of moisture, gas, and chemical (sulfates and chlorides) ions which frequently causes major durability problems on the normal Portland cement based concrete structures. This impervious characteristic of the $\mathrm{PC}$ is also beneficial to prevention of freeze-thaw damage since it rarely allows ingress of water into the PC due to its tightly formed microstructure and the binding components itself does not contain water at all. Table 2 shows the chemical resistance of the PC.

Extended experiment was conducted to compare the freezethaw resistance of $\mathrm{PC}$ to that of cement concrete. It turned out that a weight loss was almost zero when PC was under 3,650 cycles, while the corresponding weight loss of cement concrete was $26 \%$ only under 690 similar cycles ${ }^{6}$.

\subsection{Thermal properties}

Because of the nature of the binders in PC, the latter's behavior is influenced by temperature. For a standard polyester-base formulation, the deflection temperature in accordance with ASTM D 648 varies between $80^{\circ} \mathrm{C}$ and $130^{\circ} \mathrm{C}$. The specimen 
Table 1 Properties of concrete-polymer composites compared to Portland cement concrete ${ }^{4)}$

\begin{tabular}{lllll}
\hline \multicolumn{1}{c}{ Property } & \multicolumn{1}{c}{$\begin{array}{c}\text { Portland } \\
\text { cement } \\
\text { concrete }\end{array}$} & $\begin{array}{c}\text { Polymer } \\
\text { cement } \\
\text { concrete (PCC) }\end{array}$ & $\begin{array}{c}\text { Polymer } \\
\text { impregnated } \\
\text { concrete (PIC) }\end{array}$ & $\begin{array}{c}\text { Polymer concrete } \\
\text { (PC) }\end{array}$ \\
\hline Compressive strength, $\mathrm{MPa}$ & $10-60\left(>60^{*}\right)$ & $10-75$ & $100-200$ & $40-150$ \\
\hline Flexural strength, MPa & $1.5-7\left(>7^{*}\right)$ & $3-12$ & $7-35$ & $4-50$ \\
\hline Tensile strength, $\mathrm{MPa}$ & $0.6-3.0\left(>3^{*}\right)$ & $4-9$ & $4-17$ & $4-20$ \\
\hline Modulus of elasticity, GPa & $15-30$ & $10-25$ & $30-50$ & $7-45$ \\
\hline Poisson's coefficient & $0.11-0.21$ & $0.23-0.33$ & $0.20-0.25$ & $0.16-0.33$ \\
\hline Coeff. of linear thermal expansion, $10^{-6} \cdot \mathrm{K}^{-1}$ & $10-12$ & $11-15$ & $10-17$ & $10-35$ \\
\hline Water absorbability, \% & $4-10$ & $1-3$ & $0.5-1.5$ & $0.5-3$ \\
\hline Chemical resistance & poor/average & average/good & good/very good & very good/excellent \\
\hline
\end{tabular}

*For High Performance Concrete (HPC)

Table 2 Chemical resistance of polymer concret ${ }^{5}$

\begin{tabular}{lllll}
\hline $\begin{array}{l}\text { Type of } \\
\text { polymer } \\
\text { concrete }\end{array}$ & Acid & Alkali & Salt & $\begin{array}{l}\text { Oil and fat } \\
\text { mineral oil }\end{array}$ \\
\cline { 2 - 5 } & $8-9$ & $3-4$ & $9-10$ & $7-9$ \\
\hline Polyester & $9-10$ & $9-10$ & 10 & 9 \\
\hline Epoxy & $9-10$ & $9-10$ & 10 & 8 \\
\hline Furan & $8-9$ & $8-9$ & $9-10$ & $7-9$ \\
\hline Acrylic & 1 & $8-10$ & $1-7$ & $7-10$ \\
\hline Cement &
\end{tabular}

* Conceptual evaluation criteria for chemical resistance, indicating from 10 point for "Excellent" to 1 point for Failed".

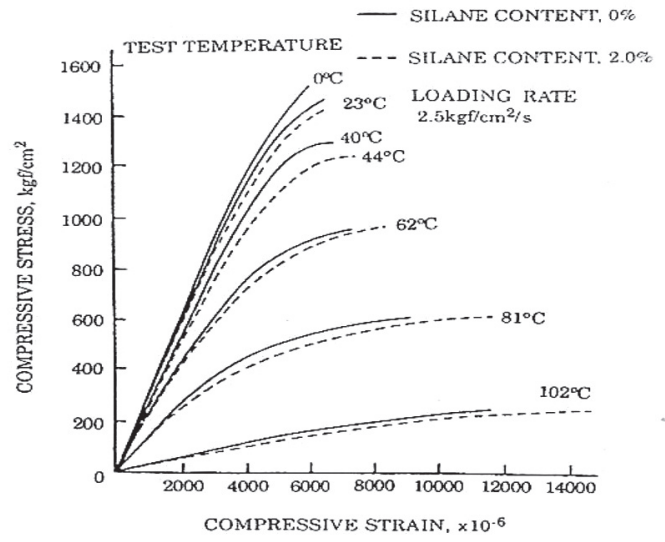

Figure 1 Compressive stress-strain curves for polymer concrete ${ }^{5)}$

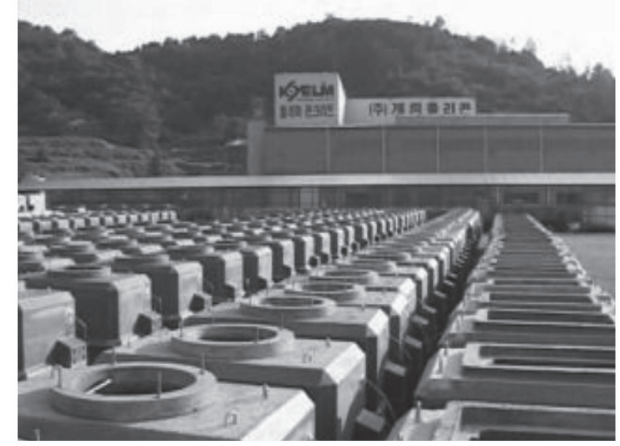

will begin to bend at temperatures around $100^{\circ} \mathrm{C}$. For current applications, however, in which the material is self-supporting, temperature does not give rise to any problems within a reasonable temperature range, as can be seen from Figure 1, which shows the characteristics of polyester polymer concrete at different temperatures.

\section{PRODUCT APPLICATIONS OF PC}

Although the polymer composites, PC, PCC, and PIC, have rough similarity in the conceptual approach, their primary applications are different in reality. While PCC and PIC are primarily used for rehabilitation and repair works, $\mathrm{PC}$ has been showing great performances in the wide range of structural applications and repair areas. This section will deal with the several examples of the precast product applications of PC with some case studies. $^{7,8)}$

\subsection{Electrical and communication facility products}

The products with advantages of electrical insulation properties, water proof and durability that polymer concrete and mortar are a cable trough used for high-speed rail line, and a power and communications manhole. The cable trough, which has a sandwich structure with the surface region reinforced with GFRP and its central region being polymer mortar, is high in bending strength and outstanding in chip resistance.

A PC manhole reduces the cross section of the members by one third of the cement concrete products, with its waterproof performance, preventing from damage by water attack which caused large barrier in communications lines (Photo 1).

\subsection{Products for water supply and drainage}

Products for water supply and drainage include pipes, manholes,

Photo 1 Communications manholes 
and their joint gadgets (Photo 2, 3).

Reinforced plastic composite is a sewer pipe appropriate for all kinds of drainage system as well as sewage and waste water, with 4-6 $\mathrm{m}$ in length with its diameter available to produce from $0.4 \mathrm{~m}$ to $2 \mathrm{~m}$. The pipe system has a sandwich structure with FRP inside and outside, with advanced resistance capabilities against external pressure, chip resistance, differential settlement of the ground, as well as excellent semi-permanent products for the freezing-thawing resistance and chemical attack.

\subsection{Products for agricultural irrigation facilities}

In order to make up for the disadvantages of conventional water ways such as a reinforced concrete bench flume and castin-place waterway, Kangwon National University and Korea Rural Community Corporation conducted a joint research and development.

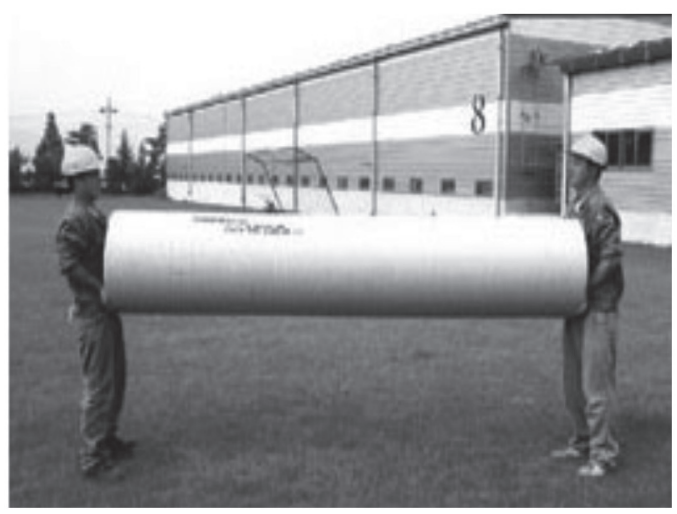

Photo 2 Reinforced plastic composite pipe

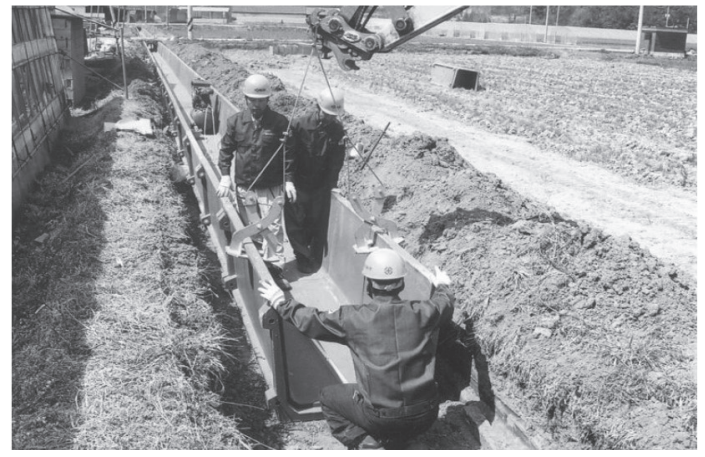

Photo 4 Installation of polymer concrete flume

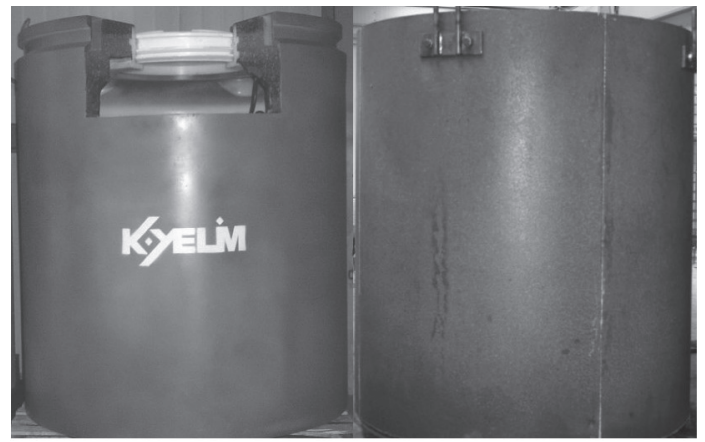

Photo 6 HIC(High Integrity Container)
They made the cross section thickness of a flume one third to one fifth of the cement concrete products, with some projected area for on the bottom plate against buoyancy caused by outer water level, and placing ribs to enlarge the moment of inertia of the sidewall (Photo 4, 5).

\subsection{High integrity container (HIC) for the disposal of nuclear waste}

With the increasing number of nuclear power generation facilities in Korea, disposal of low \& intermediate level radioactive waste in accumulation has been raised as an impending issue. A conventional imported high integrity container is high-priced and inappropriate to be used as a dimension lumber after permanent disposal.

In order to address such inconvenience, Korea Atomic Energy Research Institute developed jointly with Kyelim Polycon Corp. a

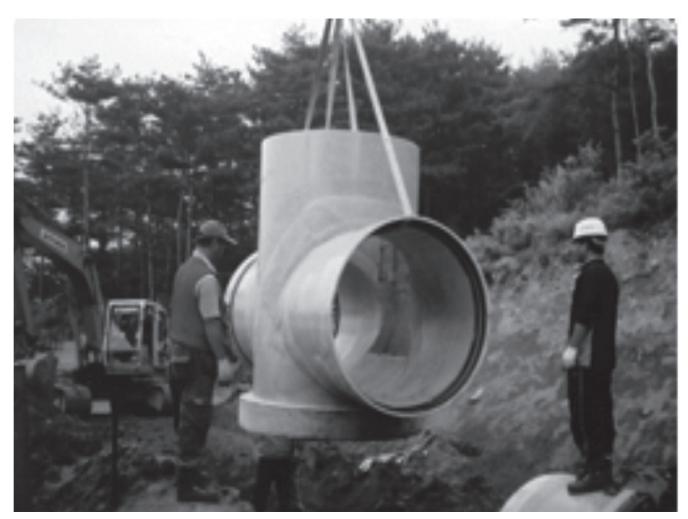

Photo 3 Polymer concrete manholes

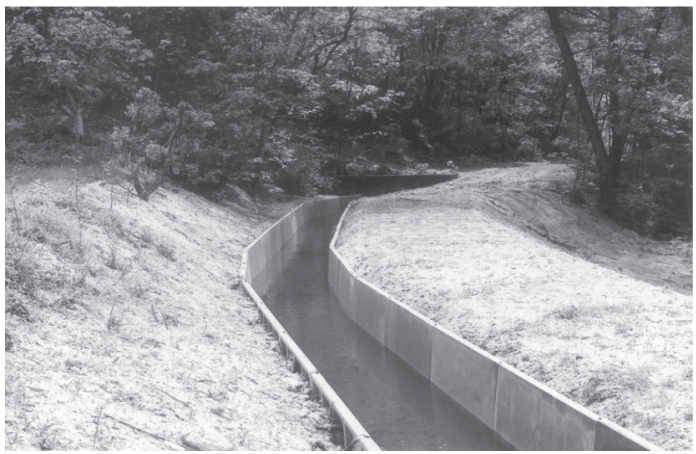

Photo 5 The installed polymer concrete flume

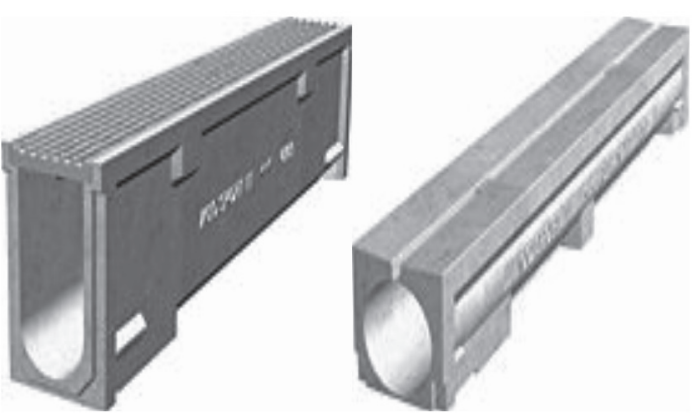

Photo 7 Polymer pre-slope trench 
PC high integrity radioactive waste container (Photo 6).

\subsection{Polymer pre-slope trench}

The drainpipe with the conventional system often causes water leakage due to its fault construction, and decay of the stagnated drainage \& sewage from unfit inclination. PC inclined drainpipe tackles the problems as it has inclination on the bottom of the drainage with its weight lighter, which facilitates transportation and construction as well as contributes to adding to the beauty of the city, providing pleasant living environment and water quality (Photo 7).

\subsection{Artificial marble and landscape products}

Artificial marble in use of $\mathrm{PC}$ can be presented similar to natural marble in quality by using pigment, natural or artificial colored aggregates. Also, it is advantageous to produce in bulk with moderate prices as the product is easy to color and mould with complicated patterns or designs. There are still some problems raised on it such as color change due to ultraviolet rays, but such weatherability can be improved by adding sun screen and sun absorbent (Photo 8).

\section{ECONOMIC ANALYSIS}

It is generally believed that a critical shortcoming of the polymer composites arises from its relatively high resources cost. However, that is not absolutely true if the concern is focused on total process costs, i.e. costs for resource, man power, production, transportation, and installation etc. In order to compare the total process costs between PC and cement concrete, actual economic analysis for precast manhole structures was carried out by the Construction Materials Laboratory at Kangwon National University, republic of Korea $^{10)}$.

According to the analysis, it turned out that the total cost was $2,461,968$ won $(2,462.00$ in U.S. dollar) when PC was used, while the corresponding cost of the cement concrete was 2,659,506 won $(2,660.00$ in U.S. dollar) $-7.4 \%$ reduction in cost. Also, there was $4.3 \%$ reduction in cost when further investigation was made on another size of the manhole structures $(4,132,834$ won -approximately 4,133.00 in U.S. dollar to $3,954,774$ won approximately 3,955.00 in U.S. dollar).

In addition to the advantage in cost efficiency, remarkable benefits were found in its excellent performances as a structural product, i.e. reduction in weight to $1 / 3$ due to the reduced thickness, fast curing, possibility of mass production, and improved durability.

To sum up, it has proved that PC is an enough competitive material based on the results from the economic analysis, especially when cost-performance efficiency was considered as the evaluation criteria.

\section{ENVIRONMENTAL EFFECTS}

The development of the sustainable construction materials has actively proceeded with an increasing interest since environmental problems have risen up as a primary issue in the past few decades. Kibert ${ }^{11)}$ categorized the sustainable construction with six principles.

Based on the principles described below, $\mathrm{PC}$ as a sustainable construction material will be evaluated and reviewed in detail ${ }^{9)}$

\subsection{Minimize Resource Consumption (Conserve)}

PC has typically 4 to 5 times greater the mechanical strength than that of cement concrete. That advantage can lead to reduction in the volume and thickness of the products and ultimately makes possible to minimize the consumption of raw materials.

\subsection{Maximize resource reuse (Reuse)}

Waste resources of PC such as fly ash, rock dust, coal mine waste, waste glass etc. can be reused as the raw material for PC products.

\subsection{Use renewable or recyclable resources (Renew/ Recycle)}

Most PC shows excellent adhesion to various construction materials such as cement concrete, stones, ceramics, wood, and bricks. Such great adhesive and bonding properties of polymeric binders make it possible to be easily renews by repair.

\subsection{Protect the natural environment (Protect nature)}

Although polymeric binders of PC seem to affect the poorer weatherability or weather resistance than inorganic materials, it is not absolutely true since most PC products tends to have a service life of more than 20 years or longer depending on the exposure conditions. Also, PC is considered to be highly-durable material against severe environmental conditions such as chemical attack, corrosion, and freeze-thaw damages.

\subsection{Create a healthy, nontoxic environment (Nontoxicity)}

Even though the polymeric binders used in PC are considered to be toxic and flammable before hardened, the safety handling procedures to prevent unexpected accidents have been adequately established. Once it hardened, it also turned out that there has been any problem reported at all.

\subsection{Pursue quality in creating the built environment (Quality)}

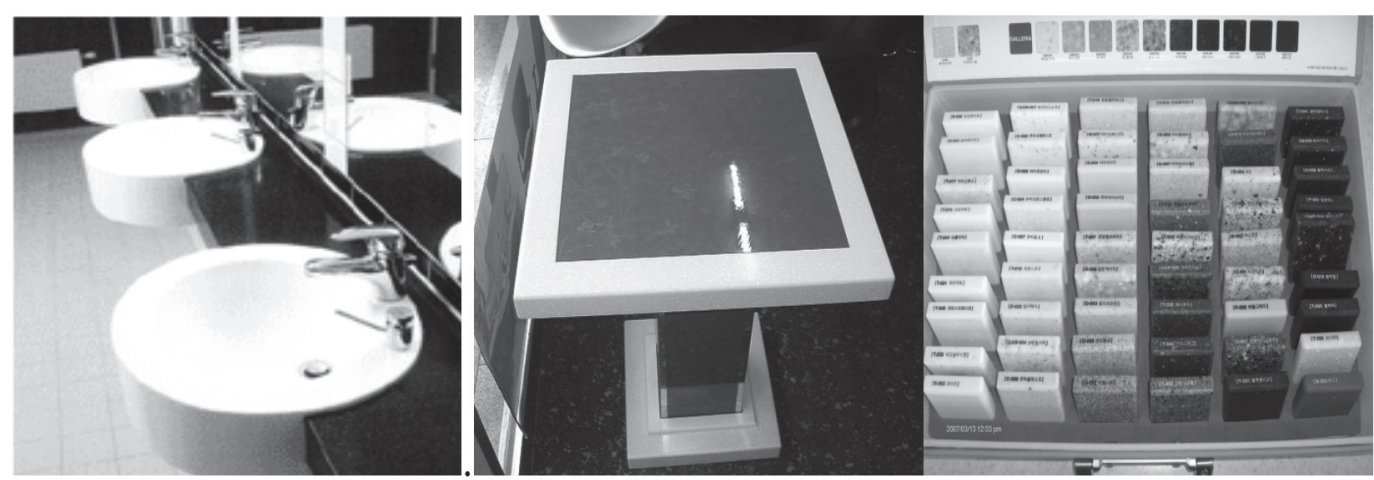

Photo 8 Artificial marble products 
In addition to the great advantages in physical and mechanical strength and chemical resistance, one of the well known excellent characteristics of $\mathrm{PC}$ is to provide aesthetic interior and exterior by creating various colors and textures coincident with the requirements for better quality in constructions.

Also, since PC has an excellent resistance to the harsh exposure conditions, it is generally considered to have a good built environment compared to other construction materials frequently used.

\section{PROSPECTS}

Much attention is being paid to whether the PC will maintain a constant market share as a promising novel construction material in the future. Based on suggestions by Fowler ${ }^{12)}$, following advances in the areas of materials, processing, and application of $\mathrm{PC}$ are expected.

\subsection{Materials}

1) Use of lower cost resins from recycled plastics for PC. Using recycled plastic also would be a better way to coincide with the sustainable development regarding environmental preservation. By emphasizing on this sustainable development, the cost of recycled plastic is likely to be decreased.

2) As cement concretes have been looking at, development of smart PC adjustable to various stimuli, i.e. deflection, extreme temperature, and stress, would be a prospective area for PC development.

3) Development of high performance PC by using accumulated experience and advanced technologies in the past 50 years.

4) $\mathrm{PC}$ with more stable properties against a temperature change

5) Considering of post recycles e.g. resins designed to easier recycles.

\subsection{Processing}

1) Processing technology that will provide better workability, placement, and finishability.

2) Development of adequate mixture proportioning methods.

3) More efficient aggregate packing.

4) Less resins incorporated into the mixture (economic advantage) but accommodate better workability.

\subsection{Applications}

1) Establish rapid, user-friendly, less labor systems for more efficient use of PC

2) Replacements for metal casting in a long-term.

- Provide a greater strength-to-weight ratio

- Improved damping properties

- Less corrosive

- Much easier just-in-time fabrication

3) Develop PC-PCC (Portland cement concrete) composites. The use of thin overlays of PC over PCC will give rise to lower cost as well as better performance especially in durability.
- Prevent ingress of corrosive ions and moisture

- Improve abrasion and chemical resistance

4) Develop intelligent PC

- Self crack sealing (self curing)

- Self straightening when excessive deflection occurred

\section{Acknowledgements}

This research was supported by Basic Science Research Program through the National Research Foundation of Korea (NRF) funded by the Ministry of Education, Science and Technology (No.2010-0009719)

\section{References}

[1] Czarnecki, L., "Essential Concrete-Polymer Composites," International Symposium Polymers in Concrete, pp.13-32, (2006).

[2] Ohama, Y., "Recent Progress in Research and Development Activities of Polymer Mortar and Concrete in Japan," $4^{\text {th }}$ Asia Symposium on Polymers in Concrete, pp.39-47, (2003).

[3] Fowler, D. W., "State of the Art in Concrete-Polymer Materials in the U.S.," $11^{\text {th }}$ International Congress on Polymers in Concrete, pp.73-79, (2004).

[4] Czarnecki, L., "Concrete-polymer Composites : Trends Shaping the Future," Int. Journal Soc.Eng.Resour. 15(1), pp.1-6, (2007).

[5] Chandra, S. and Ohama, Y., "Polymers in Concrete," CRC, pp.136-143, (1994).

[6] Wahby, W. S., "Fifty Years' History of Polymers in Concrete in Review," American Concrete Institute, International SP-214, pp.13-21, (2003).

[7] Ohama, Y., "Recent Progress in Research and Development Activities of Polymer Mortar and Concrete in Japan," $4^{\text {th }}$ Asia Symposium on Polymers in Concrete, pp.39-47, (2003).

[8] Yeon, K.-S., Choi, Y.-S. "Curent Researches and Uses of Concrete-Polymer Composites in Korea," $6^{\text {th }}$ Asia Simposium on Polymers in Concrete, (2009). (submitted paper)

[9] Yeon, K.-S., "Utilization of Polymer Concrete as Sustainable Construction Materials," Proceedings of the Fourth International Conference on Materials Engineering for Resources, pp.82-87 (1), (2001).

[10] Kangwon National University, "Manufacture and Structural Tests of Precast Polymer Concrete Manholes," Research Proposal for Korea Telecommunication, pp.205-293, (1993).

[11] Kibert, C. J., "Establishing Principles and a Model for Sustainable Construction," Sustainable Construction, Proceedings of the First International Conference of CIB $T G$ 16, (ed. C. J. Kibert), Center for Construction and Environment, University of Florida, Gainesville, Florida, pp.3-12, (1994).

[12] Fowler, D. W., "Polymers in Concrete: Where Have We Been and Where Are We Going?," American Concrete Institute, International SP-214, pp.111-117, (2003). 